DOI: $10.12731 / 2658-4034-2020-5-93-108$

УДК 378.14

\title{
ИССЛЕДОВАНИЕ ГОТОВНОСТИ УЧИТЕЛЕЙ ФИЗИКИ К РЕАЛИЗАЦИИ ТТЕМ-ОБРАЗОВАНИЯ
}

\section{Червонный М.А., Швалёва Т.В., Власова А.А.}

Цель. Комплексным подходом подготовки учителя обладает STEM-образование (science, technology, engineering, mathematics), которое позволяет обеспечить будущего учителя современными технологиями обучения школьников по инженерно-техническим и естественнонаучным направлениям. Авторы ставят целью проанализировать перспективы разработки системы педагогического STEM-образования, исследовать отночение и готовность учителей физики к STEM-подходу в школах Томской области.

Метод или методология проведения работы. В ходе исследования первоначально проведен анализ отечественной и зарубежной литературы об актуальности и развитии образовательных технологий STEM-образования. Проведены анкетирование и статистическая обработка ответов учителей физики и методистов из 57 общеобразовательных учреждений Томской области, кластеризация узких и специчфических ответов респондентов, обобщение результатов.

Результаты. Установлено, что новые требования к содержанию обучения в области естественно-научных дисииплин проявляют необходимость подготовки учителя по технологиям STEM-образования, ориентированного на решение практических и проектных задач. Доказывается, что для полноченной реализации STEM-подхода в подготовке педагога необходимы обобщённые представления теоретических и эмпирических исследований. На примере образовательных организаџий Томской области выявлено распространение различных вариаций STEM-образования. Учителя физики желают заниматься STEM-образованием. Отдаётся 
предпочтение варианту реализачии занятий со школьниками в отдельном интегрированном курсе при сохранении курса физики.

Область применения результатов. Результаты исследования могут быть применены в системе высшего педагогического образования для разработки интегрированных курсов естественных наук и «технологии» при подготовке бакалавров, разработки магистерских программ для учителей по теории и практике STEMобразования школьников.

Ключевые слова: подготовка учителей; STEM-образование; обучение физике; профильное обучение школьников.

\section{RESEARCH ON THE READINESS OF PHYSICS TEACHERS TO IMPLEMENT STEM EDUCATION}

\section{Chervonny M.A., Shvalevav T.V., Vlasova A.A.}

Purpose. STEM education (science, technology, engineering, mathematics) has a comprehensive approach to teacher training, which allows the future teacher to provide modern technologies for teaching students in engineering and natural science areas. The authors aim to analyze the prospects for developing a pedagogical STEM education system, to study the attitude of physics teachers to the STEM approach in schools in the Tomsk region.

Methodology. During the study, the analysis of Russian and international resources on the relevance and development of educational technologies for STEM education was initially carried out. The survey and statistical processing of the answers from physics teachers and methodologists from 57 general educational institutions in the Tomsk region, clustering of narrow and specific answers from respondents, and a generalization of the results were carried out.

Results. It is found that new requirements for the content of education in the field of natural sciences show the need for teacher training in STEM education technologies, focused on solving practical and project problems. It is proved that for the full implementation of the STEM approach during 
the teacher training courses, generalized representations of theoretical and empirical research are necessary. It is revealed that various types of approaches to STEM education are represented in the region. Physics teachers have a strong interest to be engaged in STEM education. Preference is given to the option when implementing the STEM classes with students in a separate integrated course while maintaining the orthodox physics course.

Practical implications. The results of the study can be applied in the system of higher pedagogical education for the development of integrated courses of natural sciences and "technology" for the bachelor's degree students, and the development of master's degree programs for teachers on the theory and practice of STEM education for schoolchildren.

Keywords: teacher training; STEM education; physics teaching; specialized training for schoolchildren.

\section{Введение}

При проектировании учебного плана профилей общеобразовательных учреждений необходимо осознавать, что профиль является способом погружения школьников в актуализированную общественно-производственную практику. Понятие профиль выходит за рамки учебного плана, определенного состава учебных предметов и образовательного пространства школы. С учётом этого примерная основная образовательная программа среднего общего образования ${ }^{1}$ с 2016 года определяет иной, чем было ранее состав профилей: технологический, естественно-научный, гуманитарный, социальноэкономический и универсальный (4 варианта). Глубокая ориентация профилей на актуальные сферы профессиональной деятельности, введение технологического профиля и исключение из состава физико-математического профиля задают иные условия по выбору учебных предметов и элективных курсов. В одном варианте универсального профиля физика присутствует, в следующем варианте произведена замена совокупности всех естественных наук на есте-

${ }^{1}$ Одобрена решением федерального учебно-методического объединения по общему образованию (протокол от 28 июня 2016 г. № 2/16-3) 
ствознание, а в двух других физика отсутствует как обязательный предмет, как и естествознание в целом. В целом во всех профилях, ввиду их конкретной практической ориентации на общественнопроизводственные сферы деятельности, иначе строится внимание на взаимосвязи предметов и их интеграцию. Можно сказать, что в профильной школе начинает осуществляться переход от группирования разных дисциплин в один блок к интеграции освоения и применения методов, знаний, инструментов различных дисциплин при решении практических и проектных задач [6, с. 64]. Эти условия требуют переосмысления основ преподавания физики в школе, акцентируя внимание на её роли в естествознании и современных технологиях, актуализации и раскрытии связей с другими науками на современном этапе. Совершенно иной уровень преподнесения физики должен быть обеспечен в технологическом профиле, где должно быть раскрыто значение физики для передовых технологий, а в естественно-научном профиле, рекомендован предмет естествознание и биофизика, где важно раскрыть современные связи физики и современной биологии и т.д. Появляется особая роль физического знания и физического эксперимента для индивидуального и командного проектирования.

Чтобы обеспечить высокий уровень практического применения школьниками предметного и интегрированного знания, создать условия для освоения ими проектных способов решения жизненных и технологических задач средствами математики, информатики и естественных наук, необходимо обеспечить соответствующий уровень подготовки учителей. Особый интерес вызывает подготовка будущих педагогов по образовательным технологиям, в которых обеспечивается мультидисциплинарный подход, реализуется межпредметное содержание, направленное на практикоориентированное и проектное обучение школьников [2, с. 52, 54-55]. Актуализируется поиск и обеспечение разнообразия теоретической и эмпирической подготовки учителей, способствующего их адаптации и успешной работе в специализированных классах (междисциплинарной направленности, школьного инженерно-технического образования, 
предуниверсариев и т.п.). Так или иначе, деятельность педагога в таких классах направлена на вовлечение детей в инженерное образование, а её основы давно и активно разрабатываются как в России, так и за рубежом. В частности проблема разработки теоретических основ проектирования моделей подготовки педагогических кадров, способных работать в специализированных инженерно-технических классах, актуальна за рубежом уже более полувека [13]. Например, в США насчитывается несколько сотен программ, направленных на вовлечение школьников в инженерию. Их обобщением и частичной координацией в структуре Американской ассоциации инженерного образования (ASEE) занимается подразделение K-12 [7]. Буква К символизирует детский сад (Kindergarten), а цифра 12 символизирует двенадцатилетнее школьное образование, в течение которого предполагается подготовка детей к инженерии, начиная с детского сада. Одна из нескольких американских идей вовлечения школьников в инженерию, широко развивающаяся в рамках К-12 Maker Movement («Движение создателей») представлена J. Pocock [14]. Последовательница идеи Maker Movement и автор книги «Создание творчества: дети, инструменты и будущее инноваций» AnnMarie Thomas определяет смысл занятий с детьми в том, чтобы получать удовольствие от дизайна и создания вещей и добавлять строгости науки, математики и анализа на ранней стадии - вот что делает инженеров [12]. Передовым комплексным подходом подготовки учителя, который позволяет обеспечить его современными технологиями обучения школьников по инженерно-техническим и естественнонаучным направлениям, обладает STEM-образование (science, technology, engineering, mathematics). Действительно, для STEM-образования характерны два ключевых компонента, что делает его подходом в образовании, а не оставляет неким набором дисциплин. Это, во-первых, интеграция предметного содержания (естественных наук, информационных и инженерных технологий, математики), во-вторых, реализация проектной деятельности, то есть выполнение проектов и исследований является основной формой учебной деятельности [6, с. 64]. 
Для полноценной реализации STEM-подхода в системе высшего педагогического образования необходимы обобщенные представления как теоретических, так и эмпирических исследований. Первый анализ зарубежного опыта обучения педагогов вузов и средних школ междисциплинарным подходам показывает, что использование ими STEAM-технологий в преподавании физико-математических дисциплин повышает успеваемость и самооценку у студентов колледжей и университетов [1, с. 325]. B STEAM базой выступает та же концепция интеграции дисциплин STEM, но с включением в общую структуру творческих дисциплин (Arts - искусства). Эффективные отечественные модели школьного STEM-образования реализуются на базах Федеральных и Региональных инновационных площадок (ФИП и РИП), в частности: в московском образовании $[7,9]$. Зарубежные исследования по изучению практики реализации STEM-образования в школе описывают ряд моделей разработки уроков, обеспечивающих их эффективность [8, с. 231-233]. В разработке материалов занятий, по причине их междисциплинарности, участвуют разные специалисты, в том числе представители вузов, специалисты компаний, образовательных ведомств. Каждая из моделей проявляет целый ряд неясностей и разногласий, возникающих среди учителей-предметников. Отметим, что практика инженерного школьного образования строится на базе деятельностного подхода, посредством экспериментирования, исследования, проектирования, конструирования и программирования [6, с. 63]. Учитывая этот момент, непосредственно предметниками, связанными со STEM-образованием, ставятся следующие вопросы: какова роль их предмета в разработке комплексных STEM-уроков; как связать содержание учебника с реальными жизненными задачами; каково соотношение исследовательского обучения с инженернотехническим проектированием [5, с. 221]. Исследователи на основе мнений педагогов задаются вопросом относительно того, какая совместная деятельность более эффективна - учителей одного предмета или разных учителей-предметников [15, с. 29-32]. В целом все исследования показывают, как в положительную сторону меняют- 
ся представления педагогов о STEM-образовании. Выделяются два направления работ педагогов-исследователей высших учебных заведений и представителей индустрии.

Bo-nервых, в России учителя общеобразовательных учреждений, как правило, преподают один предмет - математику, информатику, физику, биологию, химию или технологию. Для внедрения STEMобразования им зачастую не хватает опыта, инженерных навыков, что связано с тем, что в системе высшего педагогического образования делается акцент на теоретические предметные знания, а связь обучения с решением практических задач остаётся слабой. Поэтому важна работа по направлению популяризации STEM-технологий, организации практикоориентированных курсов повышения квалификации педагогов.

Bo-вmopbx, для полноценной реализации педагогического STEMобразования необходима разработка концептуальных основ в системе подготовки кадров высшей квалификации в России. Разработка должна быть осуществлена как на уровне бакалаврских, так и на уровне магистерских программ подготовки педагогов. На уровне бакалавриата актуальна разработка основ дисциплин, интегрирующих в теоретическом аспекте содержание наук и образовательных подходов, и обеспечивающих в практическом аспекте освоение технологий разнообразной практической деятельности со школьниками с применением различного оборудования. На уровне магистерского обучения необходимо обеспечить внедрение программы подготовки выпускников вузов как с педагогическим, так и с непедагогическим образованием, широко привлекая на программы обучения магистратуры специалистов с технологическим и инженерным образованием. В настоящее время нами насчитано не более пяти магистерских программ подготовки преподавателей в области STEM-образования, реализуемых в педагогических и других университетах страны. Одна из таких программ, разработанная в МГПУ, соотносит процесс обучения физике и развитие STEM-образования школьников.

Важные аспекты, влияющие непосредственно на процесс обучения физике, приведшие нас к руслу STEM-образования, мы определи- 
ли в начале статьи, исходя из изменений сути и состава предлагаемых профилей школьного образования. В связи с интеграцией блока школьных естественных наук и математики с инженерными и технологическими знаниями целью образования становится передача знаний школьникам и их применение на практике для решения проектным способом проблем реального мира. Однако следует учитывать, что современное обучение физике само по себе включает важные интегрированные аспекты (междисциплинарность, практикоориентированность, эксперимент и т.д.), подходящие для логики STEM-образования. В школьный курс по физике интегрированы мировоззренческие и технологически значимые разделы, такие как астрономия и космос. Темы из этих разделов активно предлагаются школьникам для проектирования как в общем, так и дополнительном образовании $[4,10]$. В этом направлении появились и интерактивные инструменты подготовки школьников, а именно инженерно-технические STEM-игры [3]. Особую роль для реализации STEM-образования играет процесс получения школьниками навыков экспериментальной и проектно-исследовательской деятельности при обучении физике. Ценность и возможности таких видов деятельности возрастают как в основном классно-урочном учебном процессе, так и в условиях внеурочной деятельности и дополнительного естественно-научного образования [11, с. 172-173].

Актуальность развития STEM-образования подкрепляется особенностями самого региона. Томская область характеризуется концентрацией научно-исследовательских институтов и вузов, в большинстве которых осуществляется широкая инженерно-технологическая подготовка студентов. В регионе выстроена деятельность Особой экономической зоны технико-внедренческого типа (ОЭ3 TВТ), направления работы которой связаны с приборостроением и электроникой, технологиями производства новых материалов, нанои биотехнологиями, медицинскими и информационно-коммуникационными технологиями. Научно-образовательный комплекс и ОЭЗ ТВТ наряду с другими элементами томской системы - индустриальными высокотехнологическими предприятиями и объединениями, 
кластерной транспортной логистикой являются важнейшими элементами инновационной экономической инфраструктуры.

Выделенные особенности региона, полученные представления о значимости образовательного процесса по физике в профильном образовании и необходимости его реорганизации в логике школьного STEM-образования, а также актуальность разработки и внедрения концептуальных основ STEM-подготовки учителей в системе высшего педагогического образования, привели нас к необходимости проведения констатирующего исследования. Целью стало исследование уровня распространения и актуальности STEM-образования для учителей физики, его соотнесение с проиессом обучения физике как основополагающим компонентом такого образования в его теоретических и практических аспектах.

\section{Материалы и методы}

Для достижения цели исследования было проведено анкетирование учителей физики 57 общеобразовательных учреждений Томской области, кластеризация узких и специфических ответов респондентов, обобщение результатов.

\section{Результаты и обсуждение}

Первый вопрос анкеты был такой: «Знакомы ли Вы с понятием STEM-образование?». На него получены ответы: нет - 18 (30,5\%); имею общие представления - 28 (47,5\%); имею представление, посещал специальные семинары по этому образованию - 8 (13,5\%); да, я знаю про это образование, профессионально занимаюсь им, реализую его в обучении детей $-3(5,1 \%)$. Ответы показывают, что значительная часть учителей $(65,5 \%)$ или не знают ничего, или имеют общее представление о STEM образовании.

В следующем вопросе изучалась готовность учителей заниматься по технологии STEM-образования, если в школе его нет. Был задан вопрос - «Если у вас не реализуется STEM-образование, хотели бы Вы проводить такое обучение для ваших школьников?». Респондентам предлагалось ответить «да», «не знаю», «нет» в двух вариантах: 
на своих уроках, в рамках отдельного курса. Распределение ответов педагогов представлено на рисунке 1.

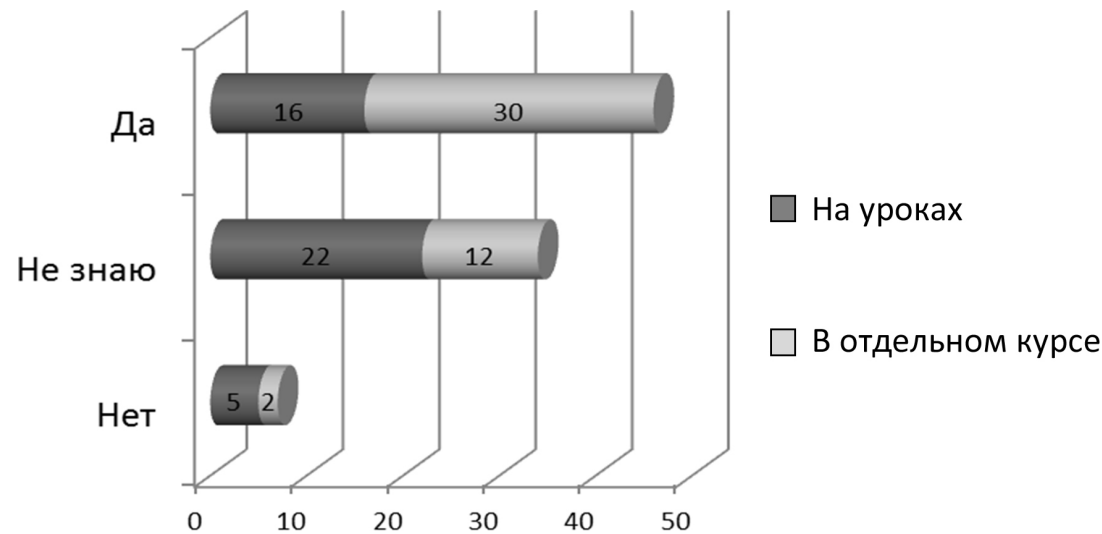

Рис. 1. Готовность учителей физики заниматься STEM образованием

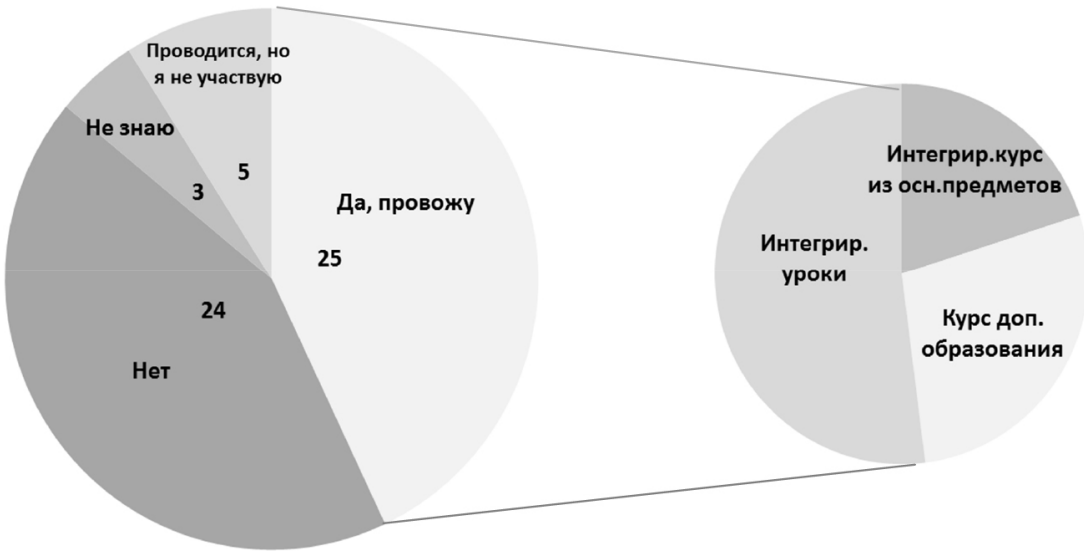

Рис. 2. Распределение ответов учителей о реализации STEM-образования в школе

Таким образом, можно утверждать, что готовность педагогов заниматься STEM-образованием со своими учениками достаточно хорошо выражена (по совокупности положительных ответов в двух вариантах). Но при этом в положительных ответах предпочтение отдается варианту занятий в отдельном курсе (30 против 16). 
Следующим был вопрос «Реализуется ли STEM-образование в Вашей школе?». Было установлено, что 30 из 57 школ, то есть чуть больше половины задействованных в опросе организаций, занимается реализацией такого образования. При этом 5 учителей физики из этих 30 школ указали, что они не участвуют в реализации такого образования (рис. 2).

Оставшиеся 25 педагогов ответили о реализации непосредственно ими STEM-образования в школе. Их ответы относительно способов реализации (см. выноску на диаграмме) распределились следующим образом, 13 - проводят интегрированные уроки, 5 - проводят интегрированный курс из основных предметов (например, физика, математика, технология), 7 - проводят курс дополнительного образования (например, курс школьного инженерного образования; курс занятий на 3 д-принтере; биофизики и т. п.).

\section{Заключение}

На основе проведенного анализа литературы и эмпирического исследования можно сделать три вывода.

1. В настоящее время происходит трансформация школьного профильного образования в сторону интеграции естественно-научных знаний, реализации актуального межпредметного знания, получения основ инженерно-технической подготовки, практикоориентированного и проектного обучения.

2. Для эффективного внедрения школьного STEM-образования требуется разработка новой системы работы с педагогическими кадрами. Выделяются два основных направления работ педагогов-исследователей высших учебных заведений и представителей индустрии.

3. На региональном уровне происходит распространение различных вариаций STEM-образования. Учителя физики выражают готовность заниматься STEM-образованием со своими учениками, отдавая при этом предпочтение варианту реализации занятий STEM-подготовки школьников в отдельном курсе, при сохранении курса физики. 
Информация о конфликте интересов. Авторы заявляют об отсутствии конфликта интересов.

Информация о спонсорстве. Исследование выполнено без участия спонсоров.

\section{Список литературы}

1. Анисимова Т. И., Шатунова О. В., Сабирова Ф. М. STЕАМобразование как инновационная технология для Индустрии 4.0 // Научный диалог. 2018. № 11. C. 322-332. DOI: 10.24224/2227-12952018-11-322-332

2. Басюк В. С., Фиофанова О.А. Анализ подходов к обновлению содержания образования: изменение роли носителей содержания образования и регуляторов образовательных стандартов // Наука и школа. 2017. № 4. С. 50-56.

3. Ечмаева Г. А., Малышева Е. Н. Инженерно-техническая STEM-игра «Индустрия 4.0 и освоение ближнего космоса» как средство политехнического воспитания старшеклассников // Вестник Московского государственного областного университета. Серия: Педагогика. 2019. № 3. C. 6-16. DOI: 10.18384/2310-7219-2019-3-6-16

4. Иванова И. В. Дополнительное космическое образование и сопровождение саморазвития личности: точки соприкосновения // Вестник Томского государственного университета. 2015. № 394. С. 201-210. DOI: $10.17223 / 15617793 / 394 / 33$

5. Нгуен Хоай Нам, Ле Суан Куанг, Нгуен Ван Хиен, Нгуен Ван Биен, Нгуен Тхи Тху Чанг, Тай Хоай Мин, Ле Хай Ми Нган Как меняются субъективные представления педагогов о STEM-образовании // Вопросы образования. 2020. № 2. C. 204-229. DOI: 1017323/18149545-2020-2-204-229

6. Обухов А. С., Ловягин С. А. Задания для практики STЕМ-образования: от суммы частных задач и учебных дисциплин к целостному деятельностному междисциплинарному подходу // Исследователь/ Researcher. 2020. № 2 (30). C. 63-80.

7. Соловьев А.И. Подготовка школьников к инженерному образованию в Москве и США// Автомобиль. Дорога. Инфраструктура. № 1 
(11). Март. 2017. URL: https://www.adi-madi.ru/madi/article/view/347/ pdf_234\# (дата обращения: 17.01.2021).

8. Сюй Шихуань, Сунг Чиа-Чи, Шин Хорн-Чжун Разработка междисциплинарного STEM-модуля для учителей средней школы: поисковое исследование // Вопросы образования. 2020. № 2. С. 204-229. DOI: $10.17323 / 1814-9545-2020-2-230-251$

9. Фиофанова О. А. Инновационные площадки - реальные институты развития // Народное образование. 2014. № 1. С. 124-130.

10. Червонный М.А., Швалева Т.В., Власова А.А. Организация проектноисследовательской деятельности школьников в области космонавтики и астрономии // Природные и интеллектуальные ресурсы Сибири (Сибресурс-24-2018). 24-я международная научно-практическая конференция. Томск, 28 ноября 2018 г. Издательство: ТУСУР. С. 125-129.

11. Червонный М. А. Возможности дополнительного физико-математического образования в подготовке в подготовке абитуриентов вузов и будущих педагогов // Вестник Томского государственного университета. 2017. № 12 (189). C. 169-176. DOI: 10.23951/1609624X-2017-12-169-176

12. AnnMarie Thomas. Making Makers: Kids, Tools, and the Future of Innovation. Maker Media, Inc. September 2014. 145 p.

13. Bocharova, J.Yu., Bagachuk, A.V., \& Safonova, M.V. The role of educational results in designing a model of pedagogical internship in engineering and technology // Perspektivy nauki i obrazovania - Perspectives of Science and Education. 2020. 45 (3). pp. 508-516. DOI: 10.32744/pse.2020.3.36

14. Pocock J. K-12 workshop is what you make of it // Prism. American Society for Engineering Education. Summer 2016. Vol. 25. no 8. p. 57.

15. Stohlmann M., Moore T. J., Roehrig G. H. Considerations for Teaching Integrated STEM Education // Journal of Pre-College Engineering Education Research. 2012. Vol. 2. no 1. pp. 28-34. DOI: 10.5703/1288284314653

\section{References}

1. Anisimova T. I., Shatunova O. V., Sabirova F. M. Nauchnyy dialog [Scientific dialogue]. 2018. no 11. pp. 322-332. DOI: 10.24224/2227-12952018-11-322-332 
2. Basyuk V.S., Fiofanova O.A. Nauka i shkola [Science and school]. 2017. no 4. pp. 50-56.

3. Yechmayeva G.A., Malysheva Ye.N. Vestnik Moskovskogo gosudarstvennogo oblastnogo universiteta [Bulletin of Moscow State Regional University]. 2019. no 3. pp. 6-16. DOI: 10.18384/2310-7219-2019-36-16

4. Ivanova I.V. Vestnik Tomskogo gosudarstvennogo universiteta [Tomsk State University Journal]. 2015. no 394. pp. 201-210. DOI: 10.17223/15617793/394/33

5. Nguyen Khoay Nam, Le Suan Kuang, Nguyen Van Khiyen, Nguyen Van Biyen, Nguyen Tkhi Tkhu Chang, Tay Khoay Min, Le Khay Mi Ngan. Voprosy obrazovaniya [Education Issues]. 2020. no 2. pp. 204-229. DOI: 1017323/1814-9545-2020-2-204-229

6. Obukhov A.S., Lovyagin S.A. Issledovatel'/Researcher [Researcher]. 2020. no 2 (30). pp. 63-80.

7. Solov'yev A. I. Avtomobil'. Doroga. Infrastruktura [Automobile. Road. Infrastructure]. no 1 (11). Mart. 2017. https://www.adi-madi.ru/madi/article/view/347/pdf_234\# (accessed January 17, 2021).

8. Syuy Shikhuan', Sung Chia-Chi, Shin Khorn-Chzhun Voprosy obrazovaniya [Education Issues]. 2020. no 2. pp. 204-229. DOI: 10.17323/18149545-2020-2-230-251

9. Fiofanova O. A. Narodnoye obrazovaniye [Public education]. 2014. no 1. pp. 124-130.

10. Chervonnyy M.A., Shvaleva T.V., Vlasova A.A. Prirodnyye i intellektual'nyye resursy Sibiri (Sibresurs-24-2018). 24-ya mezhdunarodnaya nauchno-prakticheskaya konferentsiya [Natural and intellectual resources of Siberia (Sibresurs-24-2018). 24th international scientific and practical conference]. Tomsk, November 28, 2018. Izdatel'stvo: TUSUR. pp. 125-129.

11. Chervonnyy M.A. Vestnik Tomskogo gosudarstvennogo universiteta [Tomsk State University Journal]. 2017. no 12 (189). pp. 169-176. DOI 10.23951/1609-624X-2017-12-169-176

12. AnnMarie Thomas. Making Makers: Kids, Tools, and the Future of Innovation. Maker Media, Inc. September 2014. 145 p. 
13. Bocharova, J.Yu., Bagachuk, A.V., \& Safonova, M.V. The role of educational results in designing a model of pedagogical internship in engineering and technology. Perspektivy nauki i obrazovania-Perspectives of Science and Education. 2020. 45 (3). pp. 508-516. DOI: 10.32744/ pse.2020.3.36

14. Pocock J. K-12 workshop is what you make of it, Prism. American Society for Engineering Education. Summer 2016. Vol. 25. no 8. p. 57.

15. Stohlmann M., Moore T. J., Roehrig G. H. Considerations for Teaching Integrated STEM Education. Journal of Pre-College Engineering Education Research. 2012. Vol. 2. no 1. pp. 28-34. DOI: 10.5703/1288284314653

\section{ДАННЫЕ ОБ АВТОРАХ}

Червонный Михаил Александрович, директор Центра дополнительного физико-математического и естественнонаучного образования, доцент кафедры развития физического образования, кандидат педагогических наук, доцент Томский государственный педагогический университет ул. Киевская, 60, г. Томск, Томская область, 634061, Российская Федераичи mach@tspu.edu.ru

Швалёва Татьяна Владиславовна, доцент кафедры развития физического образования, кандидат педагогических наук Томский государственный педагогический университет ул. Киевская, 60, г. Томск, Томская область, 634061, Российская Федерация tshvaleva@yandex.ru

Власова Анна Алексеевна, доцент кафедры развития физического образования, кандидат педагогических наук, доцент Томский государственный педагогический университет ул. Киевская, 60, г. Томск, Томская область, 634061, Российская Федерачия aav@tspu.edu.ru 


\section{DATA ABOUT THE AUTHORS}

Chervonny Mikhail Alexandrovich, Director of the Center for Additional Physics, Mathematics and Natural Science Education, Associate Professor of the Department of Physical Education Development, Candidate of Pedagogical Sciences, Associate Professor

Tomsk State Pedagogical University

60, Kievskaya Str., Tomsk, Tomsk region, 634061, Russian Federation

mach@tspu.edu.ru

SPIN-code: 4196-1264

ORCID: 0000-0002-4459-5726

ResearcherID: AAF-2512-2019

Scopus Author ID: 57204964813

Shvaleva Tatiana Vladislavovna, Associate Professor of the Department of Physical Education Development, Candidate of Pedagogical Sciences

Tomsk State Pedagogical University

60, Kievskaya Str., Tomsk, Tomsk region, 634061, Russian Federation

tshvaleva@yandex.ru

SPIN-code: $8808-2250$

ORCID: 0000-0001-7115-1912

Vlasova Anna Alekseevna, Associate Professor of the Department of Physical Education Development, Candidate of Pedagogical Sciences, Associate Professor

Tomsk State Pedagogical University

60, Kievskaya Str., Tomsk, Tomsk region, 634061, Russian Federation

aav@tspu.edu.ru

SPIN-code: 9362-0157

ORCID: 0000-0002-4332-2136 